Article

\title{
Design and Evaluation of a Deformable Sensor for Interstitial Pore Pressure Measurement in Concrete under Very High Stress Level
}

\author{
Abdallah Accary, Yann Malecot ${ }^{\mathbb{D}}$ and Laurent Daudeville *D \\ Université Grenoble Alpes, CNRS, Grenoble INP, 3SR, 38000 Grenoble, France \\ * Correspondence: laurent.daudeville@univ-grenoble-alpes.fr
}

Received: 19 May 2019; Accepted: 21 June 2019; Published: 27 June 2019

\begin{abstract}
Previous studies have shown the strong influence of free water saturation ratio on the triaxial behavior of concrete at high confinement. This influence of the free water is usually attributed to a pore pressure effect. This article presents an experimental method aiming at measuring the pore pressure of free water into concrete samples under very high mean stress. Two types of deformable pressure sensors were designed and tested. The first one works in hydrostatic compression while the second one acts as a flexible membrane. The two sensors give comparable results and show that pore pressure may reach several hundred $\mathrm{MPa}$ in saturated concrete sample under a maximum $400 \mathrm{MPa}$ hydrostatic compression. Such levels of pressure may explain the loss of shear strength and increase in volumetric stiffness observed on the macroscopic behavior of concrete due to the presence of free water.
\end{abstract}

Keywords: pore pressure; sensor; design; experimental method; high confinement; concrete

\section{Introduction}

The purpose of this study was to design an efficient sensor to measure the concrete interstitial pore pressure at high confining pressure. When a massive concrete structure, such as nuclear power plant, is subjected to rigid missile impact at a velocity of several hundred $\mathrm{m} / \mathrm{s}$, the material in the vicinity of the impact zone undergoes high stress levels with a mean stress level up to $1 \mathrm{GPa}$ [1,2]. Furthermore, since protective concrete structures are massive, they have a very long drying process, which induces a non-homogeneous saturation ratio. They retain a quasi-saturated core throughout their lifetime, even though their skin dries very quickly [3]. Piotrowska et al. [4] compared the dynamic and the quasi-static behaviors of concrete under confined compression; the dynamic strength of concrete is slightly greater than the quasi-static strength. Thus, in a first approximation, the dynamic and the quasi-static behaviors of concrete under confined compression can be considered as identical.

A research program was launched in 2004 aiming at characterizing concrete triaxial behavior under high confinement pressure in quasi-static conditions with the Giga press (Section 2.1). The overall program was financed by CEA-DAM (French Alternative Energies and Atomic Energy Commission-Direction of Military Applications). Several studies have been performed on samples issued from the same reference concrete called R30A7 where its compressive strength is equal to $30 \mathrm{MPa}$ at 28-days. The maximum aggregate size $(8 \mathrm{~mm})$ has been chosen with respect to specimen diameter (70 $\mathrm{mm})$. The experimental campaign has deeply investigated the influence of the water/cement ratio [5], the saturation degree [6], the effect of coarse aggregate shape [7] and the initial matrix porosity for both dried and saturated samples [8,9] on the concrete behavior under high confinement. The obtained results have pointed out that the volumetric behavior of saturated concrete is stiffer than the dry one due to a pore closure effect, as modeled by Zhutovsky [10]. The shear strength of dry 
concrete increases linearly with the confining pressure, while the shear strength of saturated concrete exhibits a plateau. These studies have also shown that the presence of free water inside concrete pores has a preponderant role on its behavior under high confinement. The influence of free water was also noticed under dynamical loading by the authors of [11,12]. Pore pressure of concrete subjected to high temperature has already been measured $[13,14]$ but, to the best of our knowledge, the pore pressure due to high mechanical loading has never been measured.

The literature reports a considerable number of drained tests on rock and sand for which the pore pressure is well controlled in the samples. The drain condition is achieved by means of pipes connecting the sample upper and lower faces with a hydraulic pump and valves [15-18]. In addition, several techniques have been devoted to develop reliable and efficient systems to control the interstitial pore pressure during triaxial tests. A fluid pump equipped with valves and pressure transducer was used by the authors of $[19,20]$, who estimated the permeability and the Biot's coefficients for tight and Bakken rocks. Such systems concern moderate stress levels and cannot be adapted to the Giga press since it would require considerable modifications. Hart [21] used the idea of a water collecting cap while performing triaxial undrained tests on rocks where the specimen was sandwiched between two caps. The pore pressure measurements were made with an endcap containing a pressure transducer (Kulite HKM-375) inserted into a Tygon sleeve at the sample bottom as reported by the author.

The study presented herein aimed at completing these previous studies by focusing on the measuring of the interstitial pore pressure into concrete at high confining pressure. First, a new device called water collecting cap, which allows the passage of the water from the confined sample to the cap cavity, by means of micro-holes, is presented. Second, two pressure sensor configurations are proposed. The geometry design, modeling and reliability of each one are then discussed. A calibration procedure is presented, which allows establishing a relation between the sensors deformation and the pore pressure. The sensors validation (Section 6) demonstrates the capability of this novel technique to measure the interstitial pore pressure into concrete under high level of confinement pressure.

\section{Experimental Set Up}

\subsection{Giga Press Overview}

The high pressure triaxial compression device is capable of generating a confining pressure up to $0.85 \mathrm{GPa}$ and an axial stress reaching $2.3 \mathrm{GPa}$ on $7 \mathrm{~cm}$ diameter specimens. It allows performing several types of tests such as triaxial, oedometric, extension at high confining pressure. The confining fluid called DOZ (di-2-ethylhexyl azelate), a non-volatile organic, inert and slightly-compressible liquid, is injected into the confinement cell through an upper opening and it is then pressurized by means of a pressure multiplying jack until the desired confinement pressure. The $13 \mathrm{MN}$ axial jack, located under the confining cell, generates the axial loading. The force is transmitted to the sample by a piston passing through the lower plug of the confining cell (Figure 1a). A displacement sensor positioned inside the press is then used to control axial displacement of the jack, while an axial force sensor and a pressure sensor placed within the confinement cell measure the sample stress state. Geo-materials samples (e.g., concrete, rocks, etc.) up to $10 \mathrm{~cm}$ in diameter can be tested within this press under undrained condition. Normally, the specimen, instrumented with deformable gauges, is then sandwiched between two principal caps made of carbide tungsten material, as shown in Figure $1 \mathrm{~b}$. The press is equipped with neither a drainage system nor a pore pressure measurement device, thus the concrete interstitial pore pressure was not evaluated before this study. 


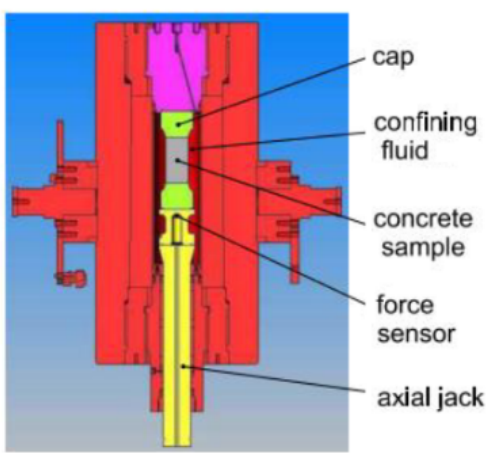

(a)

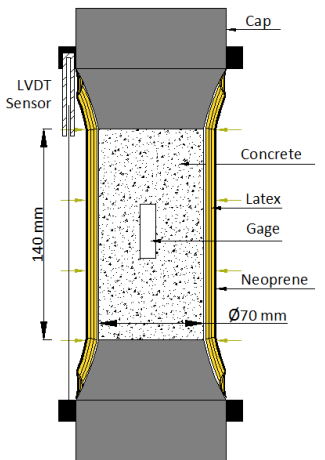

(b)

Figure 1. Giga press: (a) confining cell cross section; and (b) sample protection and instrumentation.

\subsection{Drainage System}

All previous tests on saturated concrete were done under undrained conditions with a unique measurement of the total stress components. A better understanding of the free water effect on the concrete macroscopic behavior requires a pore pressure measurement under high confinement pressure. The general idea of the drainage system presented in this paper is inspired from these previous works. The proposed drainage system consists in creating a water collecting cap under the tested specimen in which a fabricated pressure sensor is placed. The new concept consists in reducing the length of concrete sample from $(\mathrm{L}=140 \mathrm{~mm}$ to $80 \mathrm{~mm}$ ) while conserving the same diameter $(\mathrm{D}=70 \mathrm{~mm})$, as shown in Figure 2a,b. Under high confinement, brittle phenomena such as cracking are prevented and thus confined compression tests slightly depend on the specimen slenderness. A L/D ratio equal to 1 is sufficient to limit the influence of boundary conditions and to get a homogeneous stress state into the specimen. This assumption was checked in [22]. A water collecting cap made of steel is then integrated below the shortened specimen. With a cylindrical shape of $60 \mathrm{~mm}$ in height and $70 \mathrm{~mm}$ in diameter the drainage cap occupies the remaining space (Figure $2 b$ ). It serves to collect water coming from concrete during tests and contains a deformable sensor responsible of measuring the concrete interstitial pore pressure while subjected to confining pressure only. The drainage cap is composed of two parts: an upper part, which allows a straight path of the pressurized concrete water to the sensor by means of 40 micro-holes ( $1 \mathrm{~mm}$ of diameter each), and a lower part, which is a movable steel plug allowing an easy access to the cap cavity. The plug is equipped with an O-ring sealing joint, preventing both water running out of the cavity and the DOZ confining fluid filtering inside it. A hole of $1.5 \mathrm{~mm}$ in diameter is drilled transversally throughout the cap serving to connect gauge wires to the press data acquisition system (DAS), as shown in Figure 2c. 


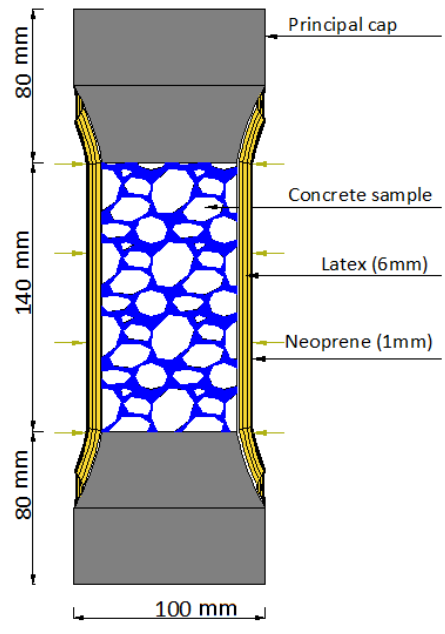

(a)

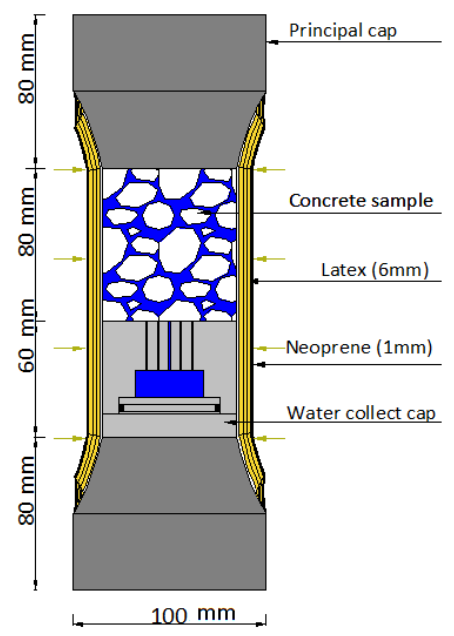

(b)

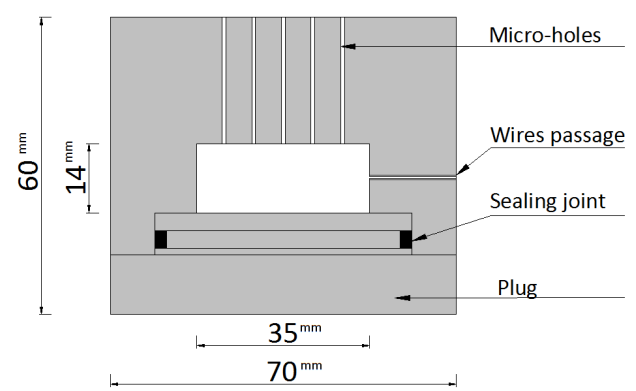

(c)

Figure 2. Water collecting cap concept: (a) initial configuration; (b) modified configuration with drainage system, shortened specimen and protection membranes; and (c) drainage cap design with micro-holes, plug and sealing joint.

\section{Pressure Sensor Concept and Design}

A classic sensor pressure would not be adequate in the presented study due to two main reasons. The first one is the need of a sensor shaped in a specific way and adapted to the case of the Giga cell, whereas the second reason is the non-availability of a small sensor capable of measuring high pressure up to several hundred MPa. In this study, the pressure was measured indirectly by means of a strain gauge glued on a deformable sensor. Based on this technique, two main configurations were adapted to achieve our purpose. The first one consists in using an aluminum cylindrical plate placed in the cap free space saturated with water. The sensor is then subjected to a hydrostatic pressure in all directions; this pressure corresponds to the interstitial pore pressure. The second configuration consists in creating a steel cylindrical membrane equipped with a sealing joint and embedded in the cap free space. This membrane deflects when the pressure to be measured is applied on its upper surface. An overview of the two sensors design and experimental procedures is presented below. The validation of both sensors on fully saturated concrete sample is discussed afterwards.

\subsection{Hydrostatic Sensor (HS)}

The first configuration consists in inserting a cylindrical aluminum plate into the cap cavity free space, as presented in Figure 3a. The plate dimensions ( $28 \mathrm{~mm}$ in diameter and $10 \mathrm{~mm}$ in thickness) are smaller than the one of the cap cavity ( $35 \mathrm{~mm}$ in diameter and $14 \mathrm{~mm}$ in height). The plate is made of aluminum because of its intermediate compressibility and its chemical resistance to the DOZ. During a hydrostatic test, the plate is surrounded in all directions by the fluid pressure to be measured. In this technique, it is supposed that the sensor is not subjected to any mechanical loading 
since its dimensions are smaller than the cap cavity dimensions. Furthermore, a deformable gauge is mounted on one of the plate surfaces serving to measure the deformation on the sensor during each test. Figure $3 \mathrm{~b}$ shows the water collecting cap, the hydrostatic sensor, the plug and the O-ring sealing joint. The aluminum plate has the following elastic characteristics: Young's modulus $E$ equal to $80 \mathrm{GPa}$ and Poisson ratio $v$ equal to 0.35 . Theoretically, the plate bulk modulus $K$ is equal to $90 \mathrm{GPa}$ (referring to Equation (1)). Since this configuration generates a hydrostatic homogeneous stress around the sensor plate, the relation between the applied pressure $p$ and the resultant volumetric strain $\epsilon_{v}$ is given by Equation (2), where $\epsilon_{v}$ is related directly to the gauge deformation $\epsilon_{x}$ by means of Equation (3). If we consider that this sensor is subjected to a confinement pressure equal to $500 \mathrm{MPa}$, the plate will deform homogeneously and in every direction with a magnitude $\epsilon_{x}$ equal to $0.184 \%$, which corresponds to a volumetric strain $\epsilon_{v}$ equal to $0.552 \%$ (positive in compression).

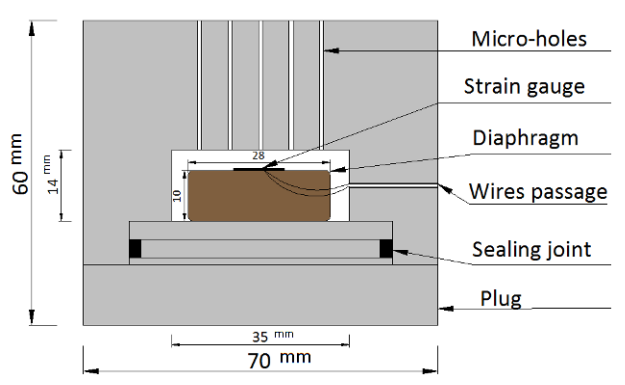

(a)

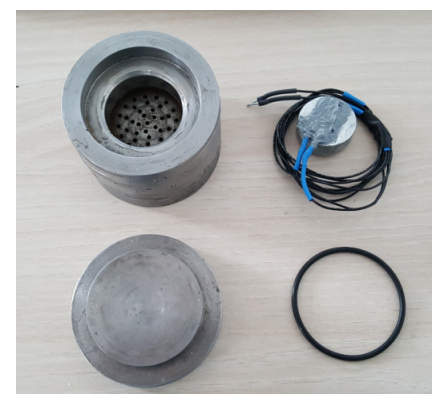

(b)

Figure 3. Aluminum sensor of hydrostatic type: (a) cross section of the collecting cap with the hydrostatic sensor dimension; and (b) picture of the cap and pressure sensor.

The relation between the Young's modulus $E$, the Bulk modulus $K$, the confining pressure $p>0$ and the plate deformations $\epsilon_{v}<0$ are given below:

$$
\begin{gathered}
K=\frac{E}{3(1-2 v)} \\
p=K \epsilon_{v} \\
\epsilon_{v}=3 \epsilon_{x}
\end{gathered}
$$

\subsection{Membrane Sensor (MS)}

\subsubsection{Geometry and Design}

The concept of the second configuration consists in creating an element that can deflect under a certain amount of pressure while remaining in the elastic domain. Therefore, a membrane-like cylindrical sensor was built, which acts as a flexible element once the pressure is applied on its upper surface (Figure 4a). The sensor has the same dimensions of the water collecting cap (approximately $35 \mathrm{~mm}$ in diameter and $14 \mathrm{~mm}$ in height). The deflection of the sensor is emphasized by the difference between its inner and outer thickness. A strain gauge is glued on the sensor back face aiming to measure its deformation once pressurized. To have a maximum gauge/wires protection from fluid leakage, a sealing joint grove was shaped at the sensor outer diameter. Figure $4 \mathrm{~b}$ shows the membrane sensor once placed inside the water collecting cap. It is worth noting that the MS sensor has two advantages over the HS one: first, the MS sensor guarantees a good sealing of the gauge/wires from the confining fluid and, second, the MS sensor is more sensitive and thus tends to amplify the output signal during measurements. 


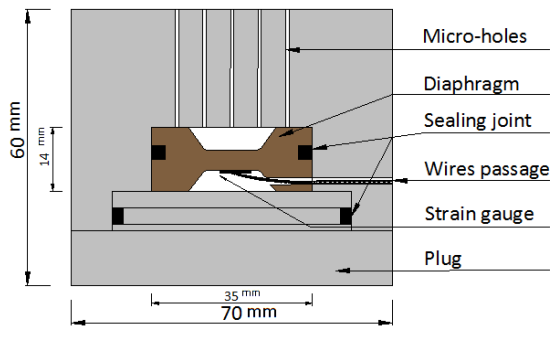

(a)

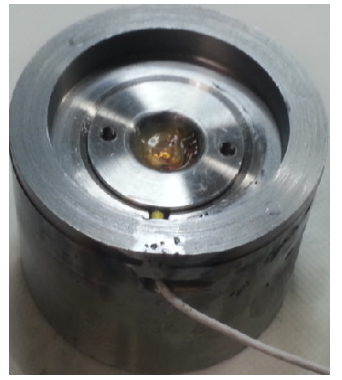

(b)

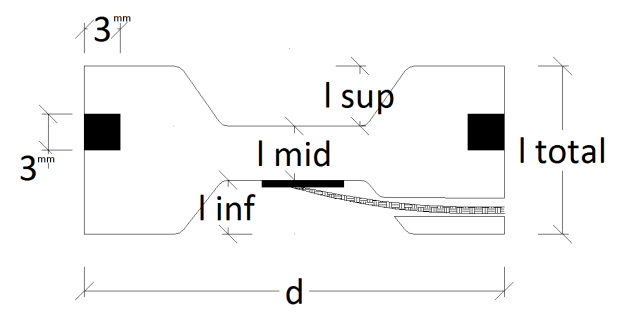

(c)

Figure 4. Steel sensor of membrane type: (a) cross section of the collecting cap with the membrane sensor; (b) picture of the cap and pressure sensor; and (c) proposed design of the membrane sensor with the gauge and sealing joint position.

In this study, it was supposed that the membrane sensor could measure a pressure as high as $400 \mathrm{MPa}$. The thickness of the sensor was optimized by a series of numerical simulations, as shown in Figure $4 \mathrm{c}$ and described in Table 1 . The total length $l_{\text {total }}$ and the diameter $d$ of the sensors were set equal to $14 \mathrm{~mm}$ and $35 \mathrm{~mm}$, while the thickness was varied among 2.5, 4 and $7 \mathrm{~mm}$. The inferior length $l_{\text {inf }}$ of the three sensors was equal to $4.5 \mathrm{~mm}$, which is considered sufficient for the gauge installation. The ideal sensor is the one which has the highest elastic deformation under pressure.

Table 1. The dimensions of the different proposed sensors in ( $\mathrm{mm})$.

\begin{tabular}{cccccc}
\hline Sensor & $\boldsymbol{l}_{\text {sup }}$ & $\boldsymbol{l}_{\text {mid }}$ (Thickness) & $\boldsymbol{l}_{\text {inf }}$ & $\boldsymbol{l}_{\text {total }}$ & $\mathbf{d}$ \\
\hline$s_{1}$ & 7 & 2.5 & 4.5 & 14 & 35 \\
$s_{2}$ & 5 & 4.5 & 4.5 & 14 & 35 \\
$s_{3}$ & 2.5 & 7 & 4.5 & 14 & 35 \\
\hline
\end{tabular}

\subsubsection{Loading and Boundary Conditions}

During each test, the sensor could be subjected to two kinds of solicitations. The first one represents the measured interstitial pore pressure, which acted on the sensor's upper and lateral surfaces up to the sealing joint. This pressure was supposed to be in equilibrium with the pressurized free water inside the concrete sample. Since the real contact conditions between the sensor and the cap plug were not well known, it was assumed that the sensor's upper and lower surfaces were constrained in displacement in the vertical direction and free in the horizontal one. Then, to simulate the behavior of the sensor, two types of boundary conditions were applied: the first one consisted in blocking the vertical displacement of all the upper and lower nodes of the sensor (Figure 5a), while the second boundary condition type, more smooth, consisted in blocking only half of the nodes, as shown in Figure 5b. The second load was more difficult to characterize and corresponded to a potential mechanical effect $(\mathrm{ME})$ due to the confining pressure. Indeed, when the confining pressure acted on the cap outer surface, it generated some strain and resulting displacement $u_{p c}$ on its inner surface (Figure 5c). Since the radial tolerance between the cap and sensor diameters was equal to $0.015 \mathrm{~mm}$ for larger values of $u_{p c}$, the confining pressure may generate some stress in the pressure sensor. 


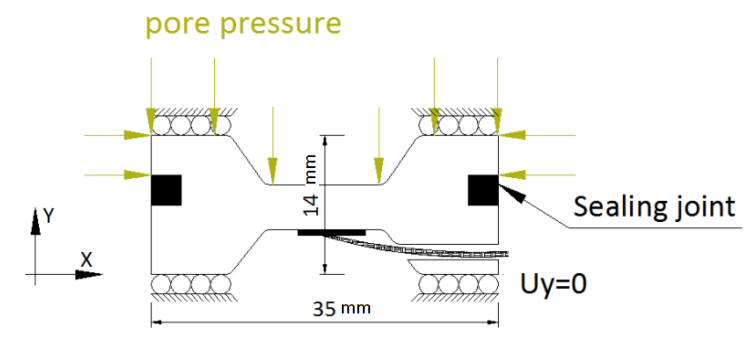

(a)

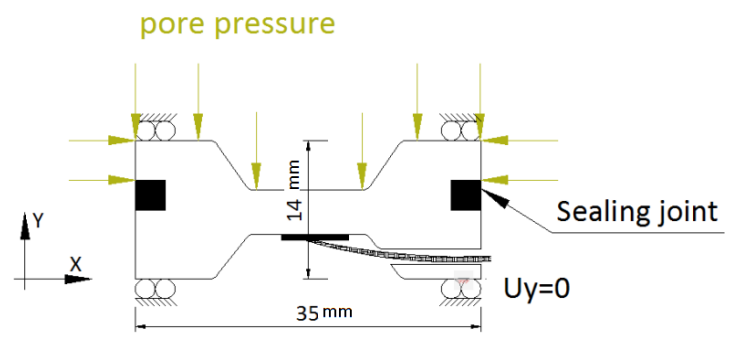

(b)

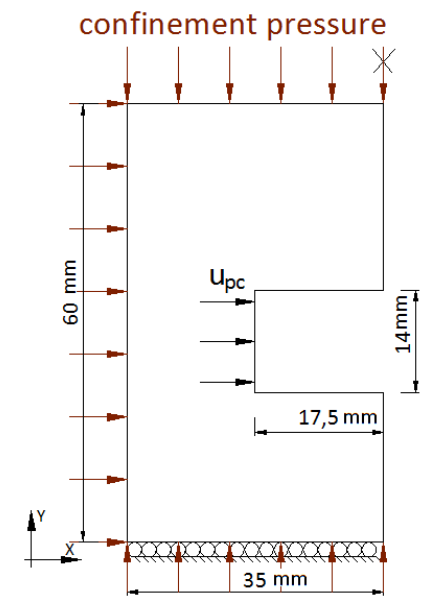

(c)

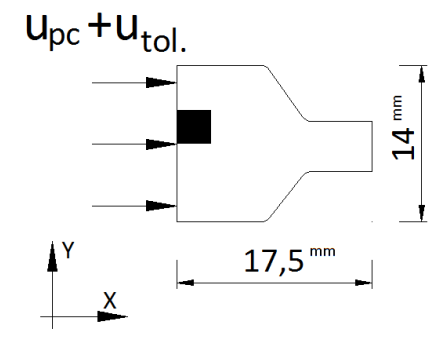

(d)

Figure 5. Loading and boundary condition used to simulate the behavior of the pressure sensor: $(\mathbf{a}, \mathbf{b})$ sensor with all nodes or half nodes fixed; (c) water collecting cap inner surface displacement due to the confinement pressure; and (d) mechanical effect on the sensor transmitted from the water collecting cap lateral surface due to confining pressure.

\subsubsection{Effect of Interstitial Pore Pressure: Stress-Strain Analysis and Geometry Validation}

The membrane sensor was designed to sustain $400 \mathrm{MPa}$ of pressure, as mentioned above. Elastic calculations were performed using Abaqus software to know the maximum stress reached in each sensor. A passage hole of $1.5 \mathrm{~mm}$ for wires connection and a groove to receive the joint of $3 \times 3$ $\mathrm{mm}$ in depth and height were created to meet the real design (Figure 6). Sensors mechanical properties were selected by considering a steel material, a Young's modulus E equal to $210 \mathrm{GPa}$ and a Poisson ratio $v$ equal to 0.3 .

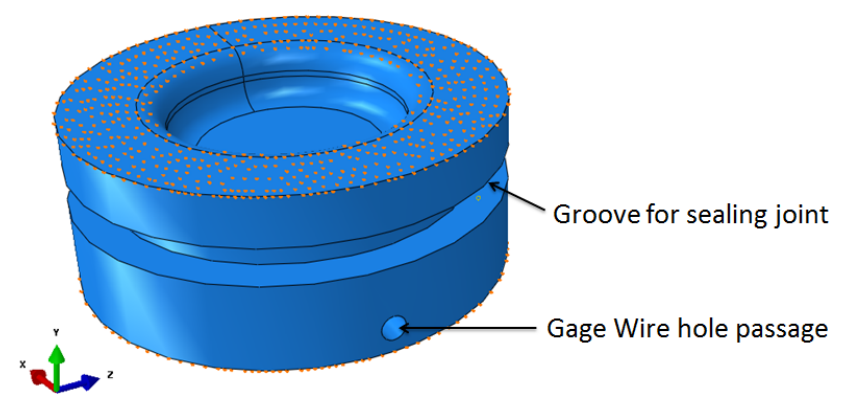

Figure 6. Sensor modeling with Abaqus FEA: applied load with boundary condition.

Table 2 presents the maximum stresses and strains obtained from the numerical simulations performed on the three sensors. Figure $7 \mathrm{a}, \mathrm{b}$ presents an example of the stress and strain distribution on the s2 sensor back face (see Table 1 for the geometry) under $400 \mathrm{MPa}$ of pressure. The strain was 
averaged on the center of the sensor back face where the gauge was glued. The results show that the thicker the sensor was, the lower the stress was. Moreover, the sensor strain tended to increase when the thickness decreased. Regarding the boundary conditions effect, the stress and strain values increased when the number of constrained nodes decreased.

Table 2. Maximum stresses and strains for the three types of sensor and for both boundary conditions.

\begin{tabular}{ccccc}
\hline $\begin{array}{c}\text { Sensor Type } \\
\text { Boundary Conditions }\end{array}$ & \multicolumn{2}{c}{$\begin{array}{l}\sigma_{V . M}(\mathbf{M P a}) \\
\text { All Nodes (Figure 5a) }\end{array}$} & $\begin{array}{l}\epsilon \mathbf{( \% )} \\
\sigma_{V . M .}(\mathbf{M P a})\end{array}$ & $\begin{array}{c}\epsilon \mathbf{( \% )} \\
\text { Half Nodes (Figure 5b) }\end{array}$ \\
\hline$s_{1}$ & 2600 & 9300 & 2800 & 10,300 \\
$s_{2}$ & 1000 & 4040 & 1240 & 4700 \\
$s_{3}$ & 590 & 2300 & 860 & 3320 \\
\hline
\end{tabular}

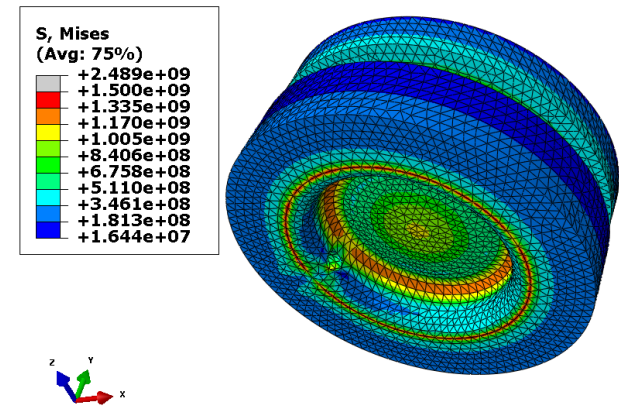

(a)

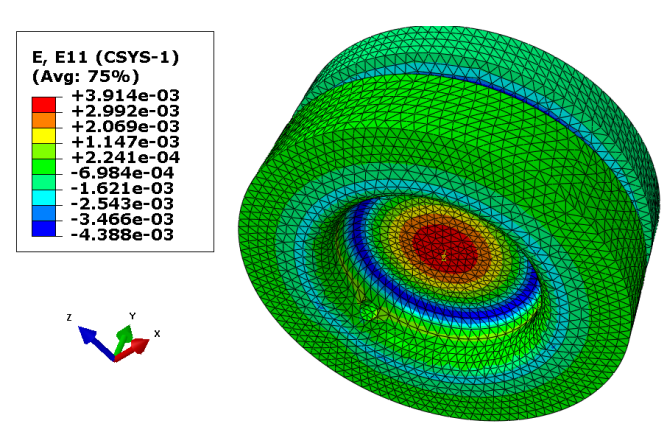

(b)

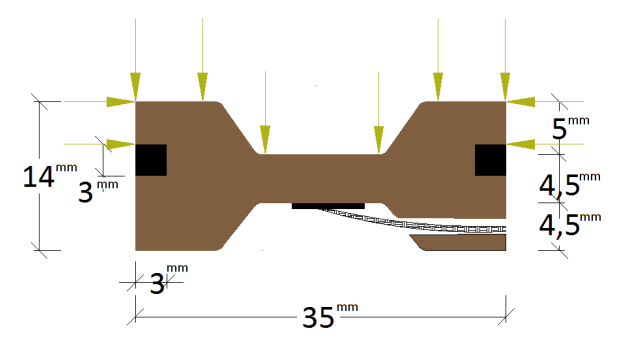

(c)

Figure 7. Sensitivity analysis: (a,b) stress and strain numerical simulation results; and (c) s2 sensor final geometry.

Finally, the sensor geometry was selected carefully to meet two major aspects. The first one was based on the sensor's ability to deflect properly while remaining in the elastic domain. Calculations showed that $s_{1}$ has a very high Misses stress, while $s_{2}$ and $s_{3}$ sensors display a maximum stress that does not exceed $1300 \mathrm{MPa}$. The second aspect is the sensor sensitivity with respect to its thickness. The $s_{1}$ sensor was eliminated since it could not resist the desired load despite its high sensitivity. On the contrary, the $s_{3}$ sensor displayed a high resistance capacity but had a low sensitivity, in particular for low and intermediate pressure. Thus, the $s_{2}$ sensor was selected for the rest of this study as it responded the most to the technical requirements (Figure 7c). A steel called TOOLLOX44 having a high elastic resistance $\sigma_{e}$ equal to $1400 \mathrm{MPa}$ was hence chosen for the material fabrication.

\subsubsection{Effect of the Confining Pressure on the Sensor}

The mechanical effect of the confining pressure on the cap and on the sensor was also studied numerically on Abaqus following the explanation detailed in (Section 3.2.2). In the first step, the water collecting cap was simulated by applying a confining pressure of $400 \mathrm{MPa}$ on its outer lateral surface (see Figure 5c). The confining pressure versus the inner cap displacement for different pressure values is plotted in Figure 8a. When the initial distance between the cap/sensor $\left(u_{t o l}\right.$. equal to $\left.0.015 \mathrm{~mm}\right)$ was 
considered, the effect of the cap displacement began to appear at $145 \mathrm{MPa}$ of confinement $\left(u_{p c}+u_{t o l}\right.$. red curve). In the second step, the resultant displacement (red curve) was applied on the $s 2$ sensor lateral surface (see Figure 5d). For simplicity, the pressure applied on the cap outer surface is presented versus the corresponding sensor deformation in Figure 8b. It was observed that the mechanical effect had a negative influence on the sensor, causing its deflection upwardly (opposite to the pore pressure direction) leading to a negative strain in its central part. In the same way, this effect started to appear on the sensor at $145 \mathrm{MPa}$ where a slight effect of the boundary conditions was observed.

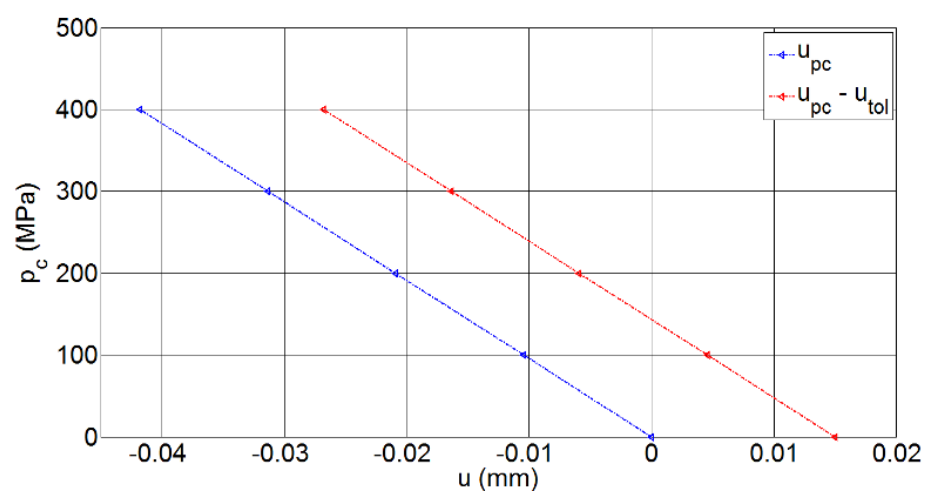

(a)

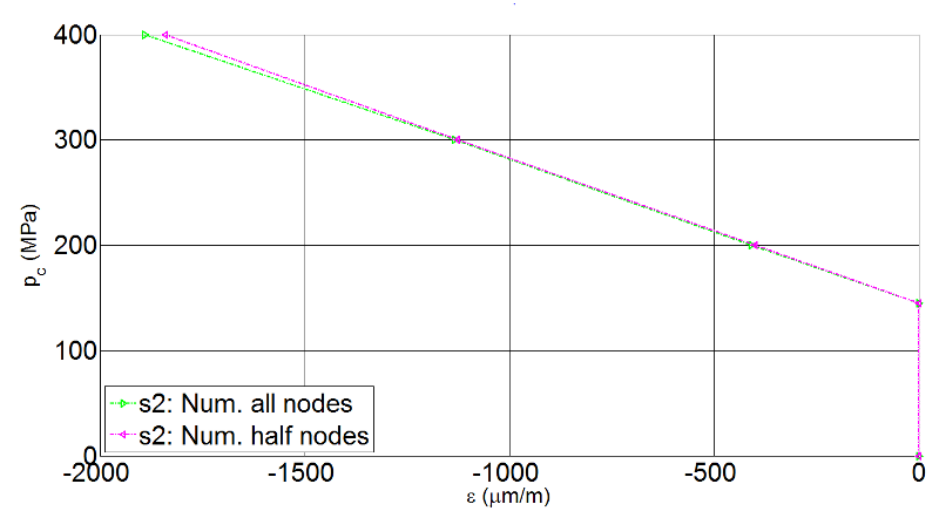

(b)

Figure 8. Effect of confining pressure on the cap and sensor: (a) water collecting cap displacement for $400 \mathrm{MPa}$ of pressure, applied pressure vs. cap inner displacement with and without counting the tolerance; and (b) sensor sensitivity after applying the tolerance, $p_{c}$ vs. $\epsilon<0$ in compression.

\section{Sensors Calibration Tests}

Once the new device, constituted of the drainage system and the sensors, was set, an experimental calibration test was performed. The main objective of this test was to establish a relation between the well known applied pressure and the sensor deformation. For the calibration tests, a hollowed cylindrical aluminum specimen was used instead of concrete sample, as discussed next.

\subsection{HS Calibration}

To calibrate the HS sensor, two types of cap/aluminum specimen arrangement were adapted. The first set (called reversed) consisted in putting the cavity free space in direct contact with the aluminum sample without using the plug (Figure 9a). This method guaranteed the passage of the confining fluid to the sensor inside the cap. The second set (called normal) was similar to the one used for pore pressure measurement, in which the cavity micro-holes met the longitudinal hole of the aluminum specimen (Figure 9b). Four hydrostatic calibration tests up to $500 \mathrm{MPa}$ of confinement were 
conducted on the HS sensor, as described in Table 3. The cavity was filled by the confining fluid (DOZ) before the beginning of each experiment. Three tests were performed without any gauge protection while the gauge of the last one was protected by a protective mastic called Dow Corning. This test aimed to study the mastic effect on the overall behavior of the sensor/gauge system. This mastic was used to limit the water conductivity on the gauge wires system since some signal perturbation were detected during pore pressure measurement tests.

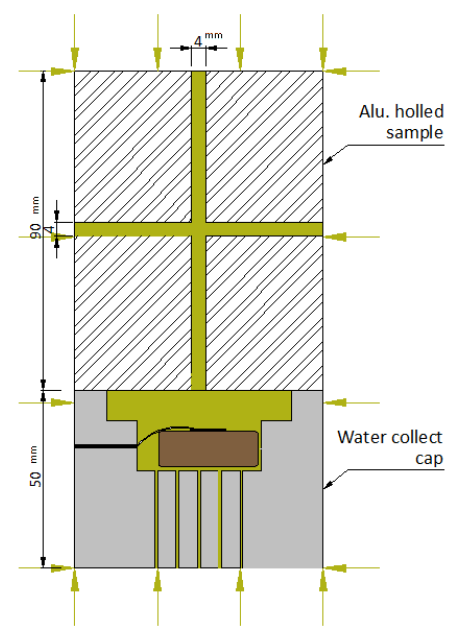

(a)

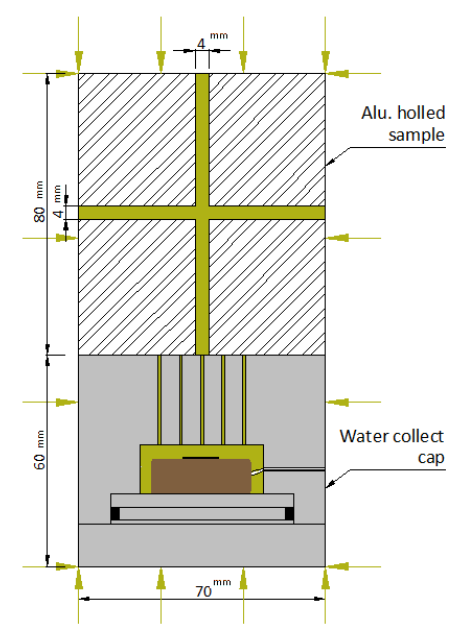

(b)

Figure 9. HS calibration test concept and results: (a) normal; and (b) reversed set.

Table 3. Description of the HS calibration test: sample/cap arrangement, condition, pressure applied and bulk modulus value.

\begin{tabular}{ccccc}
\hline Test No. & Position & Protective Mastic & $\mathbf{p}$ (MPa) & Slope K (MPa) \\
\hline HS-calib-1 & reversed & No & 500 & 940 \\
HS-calib-2 & reversed & No & 500 & 920 \\
HS-calib-3 & normal & No & 400 & 930 \\
HS-calib-4 & reversed & Yes & 400 & 930 \\
Theoretical & - & - & 500 & 900 \\
\hline
\end{tabular}

Figure 10 depicts results of calibration tests where the confining pressure is plotted versus the gauge volumetric strain. A quasi-linear increase of the sensor deformation was recorded when the sensor was pressurized. The slope of each curve represents the sensor bulk modulus. The repeatability of the results seemed to be acceptable where a maximum difference of $3 \%$ between the theoretical value and the experimental ones was observed. This difference could be due to some mechanical effect during the experiments where the sensor outer side can slightly be in contact with the cap cavity wall and thus to limit its deformation. A mean value of $930 \mathrm{MPa}$ for the bulk modulus could be deduced and was used to evaluate the concrete interstitial pore pressure. 


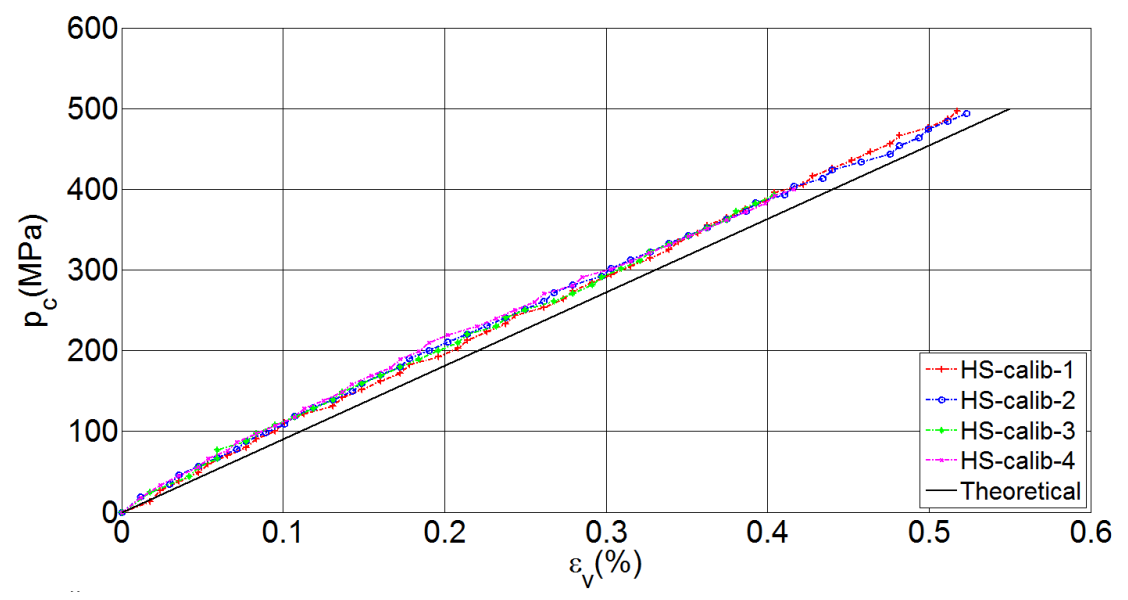

Figure 10. Results of the hydrostatic calibration tests on the HS: $p$ vs. $\epsilon_{v}>0$ in compression.

\subsection{MS Calibration}

To calibrate the MS sensor, only the normal set of the cap/aluminum cylindrical specimen was used due to the sensor shape and gauge placement, as shown in Figure 11a. The indirect effect of the confinement pressure on the sensor (called mechanical effect) was measured by using a solid aluminum sample. Only the outer side of the system was subjected to the confining pressure, as illustrated in Figure $11 \mathrm{~b}$. The experimental tests details are gathered in Table 4.

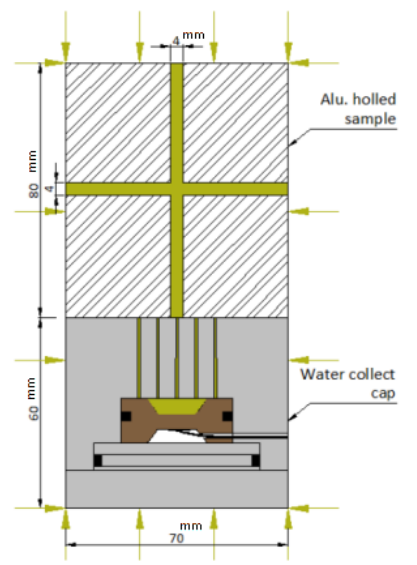

(a)

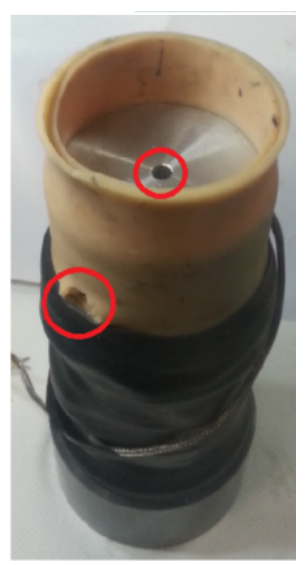

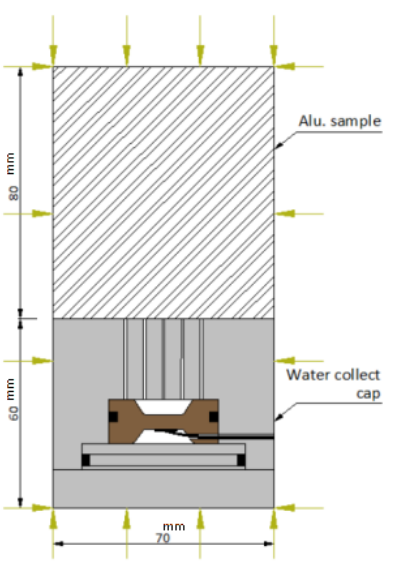

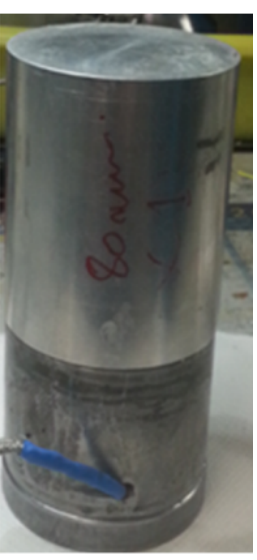

(b)

Figure 11. Membrane type sensor: (a) interstitial pore pressure calibration test; and (b) confining pressure calibration test.

Table 4. Description of the MS calibration test: condition, pressure applied and curve slope value.

\begin{tabular}{ccccc}
\hline Test Name & Purpose & Position & $\mathbf{p}$ (MPa) & Slope K (GPa) \\
\hline MS-calib & Calibration & normal & 200 & $K_{p}=73.5$ \\
MS-mech & Mechanical effect & normal & 200 & $K_{d}=-573.1$ \\
\hline
\end{tabular}

Figure 12 depicts the results of the calibration tests where the applied pressure is plotted versus the strain sensor in its central part. The experimental results were also compared with the numerical simulations shown before. First, we observed that the effect of the confining pressure caused a negative strain in the sensor, which started from the beginning pressure of the test being dissimilar to the numerical simulation curves. This means that the sealing joint filled the gap between the sensor 
and the inner cap surface and the sensor stiffness was much higher than the joint itself. Second, the experimental calibration test response was less stiff than the two numerical curves. This result could be linked directly to the choice of the boundary conditions used in the model. While comparing the numerical curves with those obtained from experiments for both kind of tests, it was clear that the numerical simulations were useful to chose the best sensor thickness but were not as precise as the experimental results due to the uncertainty about the boundary conditions.

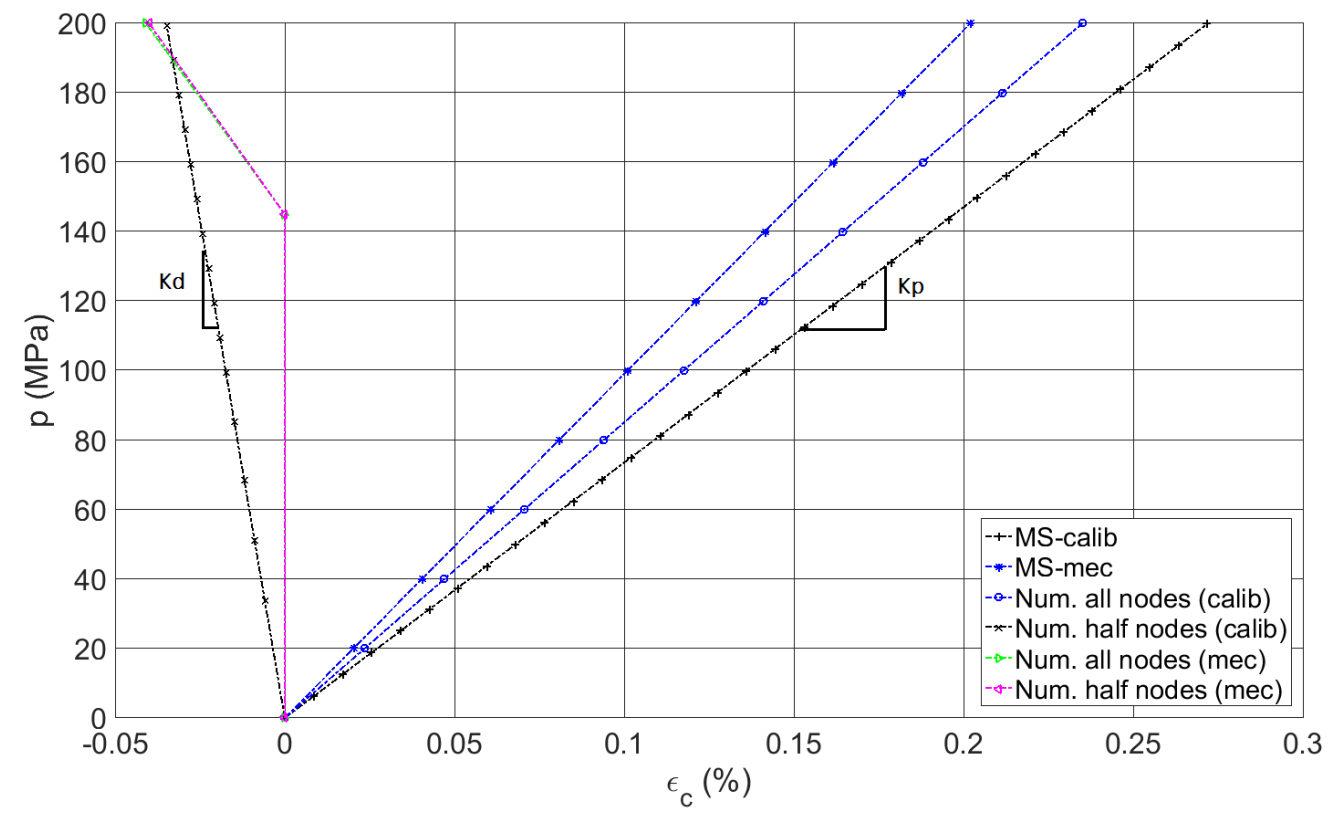

Figure 12. Experimental results of calibration test compared with the numerical calculations during a hydrostatic test.

To set a relation between the applied pressure and the strains, we supposed that the total strain $\epsilon_{t}$ was considered to be the sum of two sub-strains representing both tests (Equation (4a)). The $K_{p}$ slope was identified by performing experimentally the pore pressure calibration test while the $K_{d}$ slope was determined by performing the confining pressure calibration test (Equation (4b)). As a result, the pore pressure was calculated by using Equation (4c), where the total deformation of the sensor $\epsilon_{t}$ was measured by means of the gauge, the applied confinement $p$ was provided from the Giga press confining cell pressure sensor and $K_{d}$ and $K_{p}$ were identified from the calibration tests.

$$
\begin{aligned}
\epsilon_{t} & =K_{d}^{-1} * p_{c}+K_{p}^{-1} * p_{i} \\
\epsilon_{t} & = \begin{cases}K_{d}^{-1} * p_{c} & ; \text { if } p_{c} \neq 0 p_{i}=0 \\
\left(K_{d}^{-1}+K_{p}^{-1}\right) * p & ; \text { if } p_{i}=p_{c}=p \neq 0\end{cases} \\
p_{i} & =\left(\epsilon_{t}-\frac{p_{c}}{K_{d}}\right) * K_{p}
\end{aligned}
$$

\section{HS and MS Signals Comparison}

The signals of the pressure sensors were compared under the same amount of pore pressure, as shown in Figure 13. The gauge signal output of the MS sensor was amplified by a factor of 2.6 while comparing it to the HS sensor one. It addition, the MS sensor proved its ability to register higher strain even at low pressure since this latter was less thick and had a fully protected gauge (no contact between the interstitial fluid and the gauge). Thus, the MS sensor is highly recommended for further investigations on the concrete pore pressure influence. 


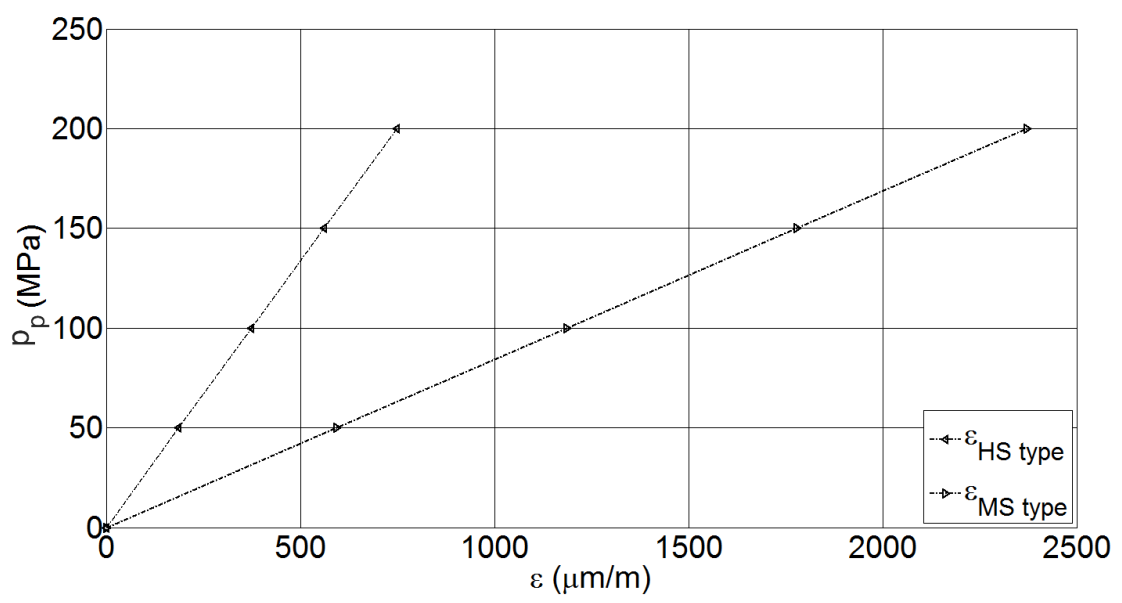

Figure 13. Comparison between the HS and MS deformations: applied pressure vs. strain.

\section{Validation of Sensors for the Measurement of Concrete Pore Pressure}

The new measurement technique was validated by means of hydrostatic test performed on a reference concrete (named R30A7), deeply investigated under high confinement pressure [5-9]. The mix properties and mechanical characteristics are given in [23] and in Table 5. These specimens were kept for more than five months in water and considered as fully saturated. Figure 14 depicts the evolution of the interstitial pore pressure as function of the confinement pressure using both pressure sensors. Since these tests aimed to validate the concept of each sensor, the confining pressure was limited to 400 and $300 \mathrm{MPa}$ on the HS and MS sensors, respectively. The sealing of the sensor was checked after each test by controlling that no confinement fluid (DOZ) was present inside the water collecting cap.

Table 5. Compositions and mechanical properties of the R30A7 ordinary concrete.

\begin{tabular}{cccc}
\hline Concrete Mix Properties & $\mathbf{K g} / \mathbf{m}^{\mathbf{3}}$ & Mechanical Properties & Values \\
\hline Cement CEM I 52.5N & 263 & Compressive strength (MPa) & 30 \\
Sand 'D' 1.8 mm & 838 & Porosity accessible to water (\%) & 12 \\
Gravel ' $\mathrm{D}$ ' 0.5-8 mm & 1007 & Slump $(\mathrm{cm})$ & 7 \\
Water & 169 & W/C ratio & 0.64 \\
\hline
\end{tabular}

It is clear from the experimental results that both sensors had a very close response to the concrete interstitial pore pressure despite the difference in their concept. The concrete pore pressure measured by the HS and MS sensors remained at a quasi-null value until $40 \mathrm{MPa}$ of confinement pressure. This behavior could be due to two possibilities. The possibility is that the cap saturation procedure was not perfect and a small amount of air was trapped inside it. In this case, the pore pressure could not increase before the free air was purged outside the cap micro-holes. The second possibility was due to the saturation of the concrete sample being lower than $S_{r} \leq 100 \%$. The pores not filled with water could delay the increase of pore pressure. Both reasons might explain what was observed for both tests where the pore pressure started to increases when all free pores were closed. After this stage, a rapid increase of the pore pressure was noticed for both tests, reaching 350 and $200 \mathrm{MPa}$ for the HS and MS sensors, respectively. The observed gradual increase of the pore pressure for both tests could be explained by the progressive collapse of the concrete pores exhibited under high confinement pressure. 


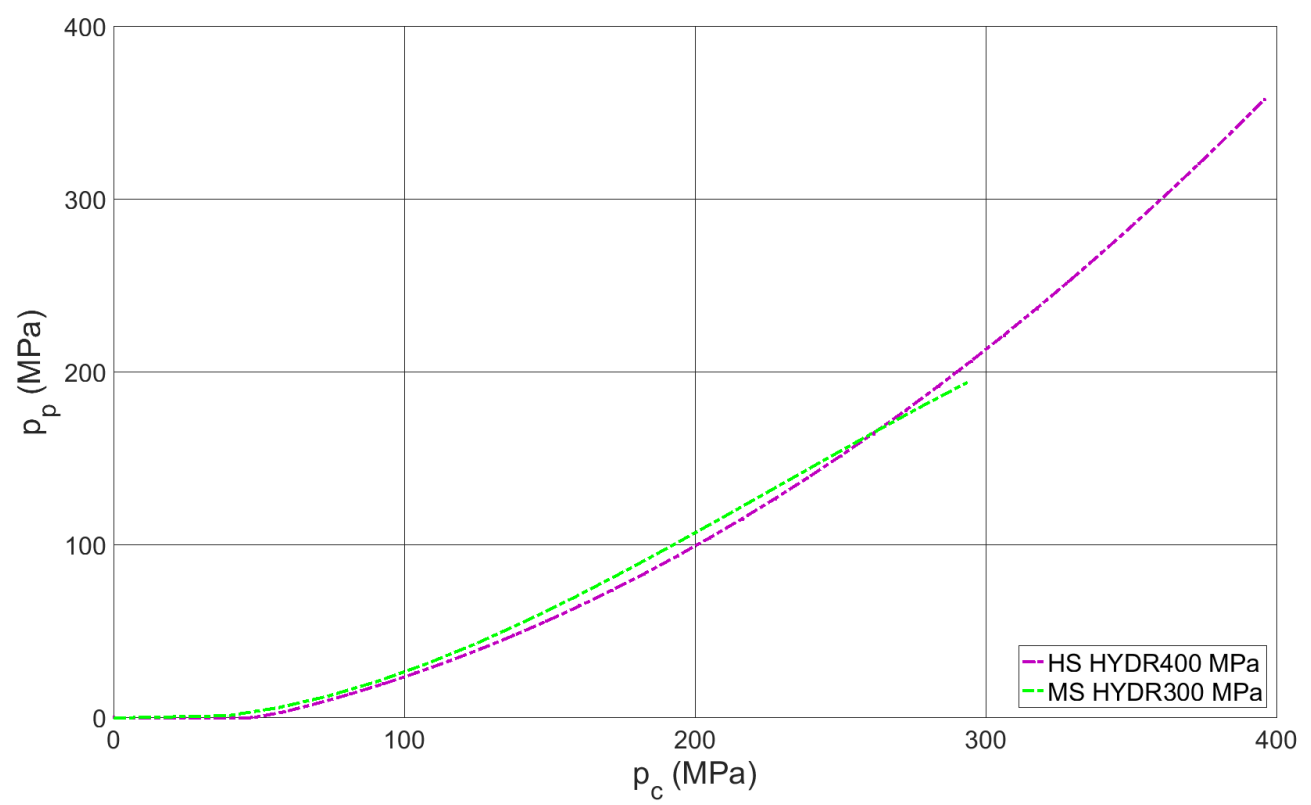

Figure 14. Validation of HS and MS sensors: interstitial pore pressure measurement vs. confinement pressure for R30A7 concrete samples under hydrostatic conditions.

\section{Conclusions and Outlooks}

In this paper, a novel method aiming to measure the interstitial pore pressure inside concrete subjected to high confinement is presented. The new technique consists in creating a water collecting cap having micro-holes on its upper side. Two types of deformable sensors were developed, as described in this paper. The first one is a hydrostatic sensor type (HS) while the second one is a membrane effect sensor type (MS). Numerical simulations analyses of the MS behavior were used to optimize the sensor sensitivity and to choose the resistance of the steel material. Sensors were first validated by means of calibration tests, during which well-known confinement pressure or pore pressure was applied. Results of calibration tests permitted establishing a relation between the applied pressure and the sensor deformation recorded by means of strain gauge placed on each sensor. Hydrostatic tests on a very wet R30A7 concrete type were performed to validate the device and the sensors concept. The interstitial pore pressure measurement conducted using both sensors showed very close values. The pore pressure reached $350 \mathrm{MPa}$ for $400 \mathrm{MPa}$ of confinement. The new technique provided in this paper will allow validating a mesoscopic model of concrete taking into account the interstitial pressure due to the water phase. Such a mesoscopic model may help at better understanding the effect of free water on the macroscopic behavior of concrete under high confinement.

Author Contributions: Experiment, A.A.; writing, A.A., Y.M. and L.D.; and supervision, Y.M. and L.D.

Funding: This experimental study and the GIGA press were financially supported by CEA-DAM (French Alternative Energies and Atomic Energy Commission-Direction of Military Application).

Conflicts of Interest: The authors declare no conflict of interest.

\section{References}

1. Daudeville, L.; Malecot, Y. Concrete structures under impact. Eur. J. Environ. Civ. Eng. 2011, 15, $101-140$. [CrossRef]

2. Gran, J.K.; Frew, D.J. In-target radial stress measurments from penetration experiments into concrete by ogive-nose steel projects. Int. J. Impact Eng. 1979, 19, 715-726. [CrossRef]

3. Baroghel Bouny, V.; Mainguy, M.; Lassabatere, T.; Coussy, O. Characterization and identification of equilibrium and transfer moisture properties for ordinary and high performance cementitious materials. Cem. Concr. Res. 1999, 29, 1225-1238. [CrossRef] 
4. Piotrowska, E.; Forquin, P.; Malecot, Y. Experimental study of static and dynamic behavior of concrete under high confinement: Effect of coarse aggregate strength. Mech. Mater. 2016, 92, 164-174. [CrossRef]

5. Vu, X-H.; Malecot, Y.; Daudeville, L.; Buzaud, E. Effect of the water/cement ratio on concrete behavior under extreme loading. Int. J. Numer. Anal. Methods Geomech. 2009, 33, 1867-1888. [CrossRef]

6. Vu, X-H.; Malecot, Y.; Daudeville, L.; Buzaud, E. Experimental analysis of concrete behavior under high confinement: Effect of the saturation ratio. Int. J. Solids Struct. 2009, 46, 1105-1120. [CrossRef]

7. Piotrowska, E.; Malecot, Y.; Ke, Y. Experimental investigation of the effect of coarse aggregate shape and composition on concrete triaxial behavior. Mech. Mater. 2014, 79, 45-57. [CrossRef]

8. Zingg, L.; Baroth, J.; Malecot, Y. Influence of cement matrix porosity on the triaxial behavior of concrete. Cem. Concr. Res. 2016, 80, 52-59. [CrossRef]

9. Malecot, Y.; Zingg, L.; Briffaut, M.; Baroth, J. Influence of free water on concrete triaxial behavior: The effect of porosity. Cem. Concr. Res. 2019, 120, 207-216. [CrossRef]

10. Zhutovsky, S.; Karinski, Y.S.; Yankelevsky, D.Z.; Feldung, V.R. Multiscale model for the prediction of equation of state for cement paste and mortar. Int. J. Solids Struct. 2018, 152, 324-335. [CrossRef]

11. Wang, H.; Wanga, L.; Song, Y.; Wang, J. Influence of free water on dynamic behavior of dam concrete under biaxial compression. Constr. Build. Mater. 2016, 112, 222-231. [CrossRef]

12. Zhou, J.; Chen, X.; Wu, L.; Kan, X. Influence of free water content on the compressive mechanical behaviour of cement mortar under high strain rate. Sadhana 2011, 36, 357. [CrossRef]

13. Mindeguia, J.C.; Pimienta, P.; Noumowé, A.; Kanema, M. Temperature, pore pressure and mass variation of concrete subjected to high temperature-Experimental and numerical discussion on spalling risk. Cem. Concr. Res. 2010, 40, 477-487. [CrossRef]

14. Kalifa, P.; Menneteau, F.D.; Quenard, D. Spalling and pore pressure in HPC at high temperatures. Cem. Concr. Res. 2000, 30, 1915-1927. [CrossRef]

15. Archambault, G.; Poirier, S.; Rouleau, A.; Gentier, S.; Riss, J. Pore pressure behavior in undrained triaxial shear tests on joints. In Proceedings of the 9th ISRM Congress, Paris, France, 25-28 August 1999; pp. 741-746.

16. Sulem, J.; Ouffroukh, H. Shear banding in drained and undrained triaxial tests on saturated sandstone: Porosity and permeability evolution. Int. J. Rocks Mech. Min. 2012, 43, 292-310. [CrossRef]

17. Nowakowski, A. The law of effective stress for rocks in light of results of laboratory experiments. Arch. Min. Sci. 2012, 57, 1027-1044.

18. Hu, C.; Skoczylas, F. Poromechanical Properties of a Sandstone Under Different Stress. Rock Mech. Rock Eng. 2018, 51, 3699-3717. [CrossRef]

19. Ling, K.; He, J.; Peng P. Comparisons of Biot's Coefficients of Bakken Core Samples Measured by Three Methods. In Proceedings of the 50th US Rock Mechanics/Geomechanics Symposium, Houston, TX, USA, 26-29 June 2016.

20. Ling, K.; He, J.; Peng, P.; Han, G.; Zhang H. Determining the permeability of tight rock with gas transient flow. J. Nat. Gas Sci. Eng. 2013, 15, 1-7. [CrossRef]

21. Hart, D.J.; Wang, H.F. Laboratory measurements of a complete set of poroelastic moduli for Berea Sandstone and Indiana Limestone. J. Geophys. Res. 1995, 100, 17741-17751. [CrossRef]

22. Vu, X-H.; Malecot, Y.; Daudeville, L. Strain measurements on porous concrete samples for triaxial compression and extension tests under very high confinement. J. Strain Anal. Eng. Des. 2008, 44, 633-657.

23. Malecot, Y.; Daudeville, L.; Dupray, F.; Poinard, C.; Buzaud, E. Strength and damage of concrete under high triaxial loading. Eur. J. Environ. Civ. Eng. 2010, 14, 777-803. [CrossRef]

(C) 2019 by the authors. Licensee MDPI, Basel, Switzerland. This article is an open access article distributed under the terms and conditions of the Creative Commons Attribution (CC BY) license (http://creativecommons.org/licenses/by/4.0/). 